\title{
Expeditious syntheses of 3,4-dihydroisocoumarins and phthalides via a Heck-Matsuda reaction.
}

\author{
Forni, J.A.; Biajoli, A.F.P.; da Penha, E.T.; Correia, C.R.D. \\ Instituto de Química, Universidade Estadual de Campinas, UNICAMP, C.P. 6154, CEP 13084-971, \\ Campinas, São Paulo, Brasil \\ *roque@iqm.unicamp.br
}

Keywords: 3-aryl-3,4-dihydroisocoumarin, phthalides, Heck-Matsuda.

\section{INTRODUCTION}

The 3-aryl-3,4-dihydroisocoumarins and phthalides are families of natural products that exhibit an extensive list of biological activities. ${ }^{1}$ For example, the sweetener phyllodulcin is more effective than sucrose $^{1 \mathrm{a}}$, and isoochracinic acid, is a phthalide that causes the black spot disease on Japanese pears ${ }^{1 \mathrm{~b}}$.<smiles>COc1cc(C2Cc3cccc(O)c3C2)ccc1O</smiles>

(1)

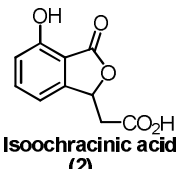

(2)
Figure 1. Examples of isocoumarins and phthalides.

Employing Heck-Matsuda (HM) conditions ${ }^{2}$, we developed an efficient protocol for the synthesis of these cores structures using arenediazonium salt $\mathbf{3}$.

\section{RESULTS AND DISCUSSION}

We started with $p$-AcO-styrene 4 since previous results suggested its advantageous use in $\mathrm{HM}$ reaction. ${ }^{3}$ Initial tests showed that besides formation of the Heck adduct $\mathbf{5}$, we also observed compound 6. After some experimentation, we obtained the cyclized product 7c in $63 \%$ yield. Its formation is readily explained by both the acidification of the medium and the electronic nature of 6 .

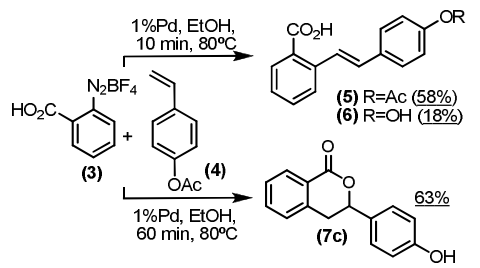

Scheme 1. Regiocontrolled syntheses of isocoumarin.

In order to investigate the electronic influence of the substituent, we proceed with arylation of olefins bearing EWG. Thus, the reaction of $\mathbf{3}$ with methyl vinyl ketone gave the anticipated phthalide $\mathbf{8 a}$ in $65 \%$ yield.

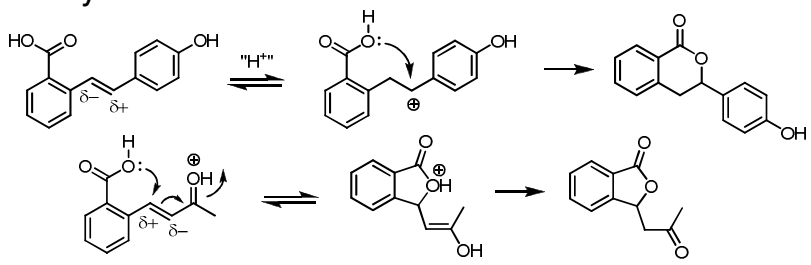

The scope of this reaction was explored and the results are summarized in table 1.

Table 1. Synthesis of dihydroisocoumarins and phthalides.

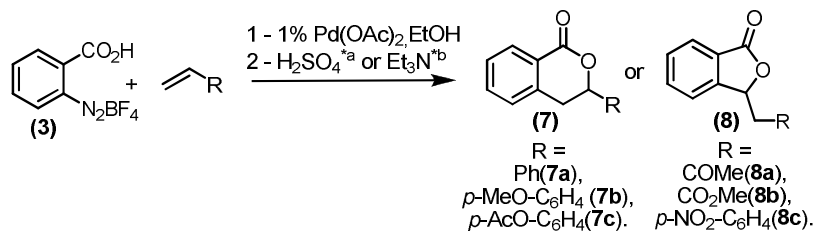

\begin{tabular}{ccc|ccc}
\hline \hline$\#$ & $\mathrm{R}$ & $\%$ & $\#$ & $\mathrm{R}$ & $\%$ \\
\hline $\mathbf{7 a}^{* \mathbf{a}}$ & $\mathrm{Ph}$ & 85 & $\mathbf{8 a}$ & $\mathrm{COMe}$ & 65 \\
\hline $\mathbf{7 b}$ & $4-\mathrm{MeO}-\mathrm{C}_{6} \mathrm{H}_{4}$ & 45 & $\mathbf{8 b}$ & $\mathrm{CO}_{2} \mathrm{Me}$ & 82 \\
\hline $\mathbf{7 c}$ & $4-\mathrm{AcO}-\mathrm{C}_{6} \mathrm{H}_{4}$ & 63 & $\mathbf{8 c ^ { * }}$ & $4-\mathrm{NO}_{2}-\mathrm{C}_{6} \mathrm{H}_{4}$ & 68 \\
\hline \hline
\end{tabular}

In agreement with our mechanistic proposal (figure 2), we found that olefins bearing EWG provide the phthalide core $(\mathbf{8 a}, \mathbf{8 b}, \mathbf{8} \mathbf{c})$ whereas those bearing EDG generate the isocoumarin core $(\mathbf{7 a}, 7 \mathbf{b}, 7 \mathbf{7 c})$. The one-pot cyclization took place only in the cases of $\mathbf{7 b}, 7 \mathbf{c}$ and $\mathbf{8 a}$. In the others cases, the desired product was obtained by further addition of acid (7a) or base $(\mathbf{8 b}, \mathbf{8 c})$.

\section{CONCLUSION}

An expeditious synthesis of 3,4-dihydroisocoumarins and phthalides was developed. The choice of a 6 or 5 membered ring is made based upon the electronic nature of the group attached to the olefin. Therefore, EDG and EWG groups give the isocoumarin and phthalides, respectively.

\section{ACKNOWLEDGEMENTS}

FAPESP, CNPq.

\section{REFERENCES}

1. (a) Dick, W.E.; Hodge, J.E. J. Agric.Food Chem. 1978, 26, 723725. (b) Kameda,K.; Namika, M. Chem. Lett. 1974, 1491.

2.(a) Heck, R.F.; Nolley, J.P J. Org. Chem. 1972, 37, 2320. (b) Kikukawa, K.; Matsuda, T. Chem. Lett. 1977, 159-162

${ }^{3 .}$ Moro, A. V.; Cardoso, F. S. P., et al. Tetrahedron Lett. 2008, 49, 5668-5671.

Figure 2. Rationale for the formation of products. 